INDO GLOBAL JOURNAL OF

PHARMACEUTICAL SCIENCES

ISSN 2249- 1023

\title{
Mechanism of Diabetes Therapy via Natural Plant Products
}

\author{
Rashmi K. Ambasta * \\ Department of Biotechnology, Delhi Technological University (Former Delhi College of Engineering), Delhi, India
}

Address for Correspondance: Rashmi K. Ambasta, rashmiambasta@dce.edu ; rashmiambasta@gmail.com

\begin{abstract}
Keywords Diabetes mellitus;

Azadirachtin;

Natural Plant

Products.

ABSTRACT: Natural plant product has been used from ancient time for the treatment of Diabetes but the exact mechanism (or target downstream signaling protein) of its action is not known. High Blood sugar for prolonged period can initiate problems related to cardiovascular, muscular, retinopathy system. Hence these diabetic related problem can be inhibited by the use of natural plant products like azadirachtin from neem, curcumin from turmeric and other unidentified biomolecules etc. We set out to investigate the best biomolecule from plant product for Diabetes and identify the exact mechanism of its action. We have used PharmMapper software to identify targets of these natural plant products and verified those targets in in vitro system. We have also docked the identified target protein with the biomolecule and prepared a comparative chart for the best target protein and biomolecules from plant products for diabetes. We have also confirmed the target protein via FISH and western blotting analysis in Diabetes system and diabetic related disorder in mice. Hence our work hints towards the best identified biomolecule azadirachtin from neem and we also perform a comparative analysis of target protein of azadirachtin with generally used drug Metformin. Therefore it can be concluded the azadirachtin is the best screened anti-diabetic plant product, which can be used to inhibit diabetic related disorder in prolonged Diabetes. We also conclude that the target protein of azadirachtin and metformin is very similar in its action with minor variation. (C) 2016 iGlobal Research and Publishing Foundation. All rights reserved.
\end{abstract}

Conference Proceedings: International Conference on Advances in Plant and Microbial Biotechnology (PMB2017); JIIT, Noida: February 02-04, 2017

Indo Global Journal of Pharmaceutical Sciences( ISSN 22491023 ; CODEN- IGJPAI; NLM ID: 101610675) indexed and abstracted in EMBASE(Elsevier), SCIRUS(Elsevier),CABI, CAB Abstracts, Chemical Abstract Services(CAS), American Chemical Society(ACS), Index Copernicus, EBSCO, DOAJ, Google Scholar and many more. For further details, visit http://iglobaljournal.com 